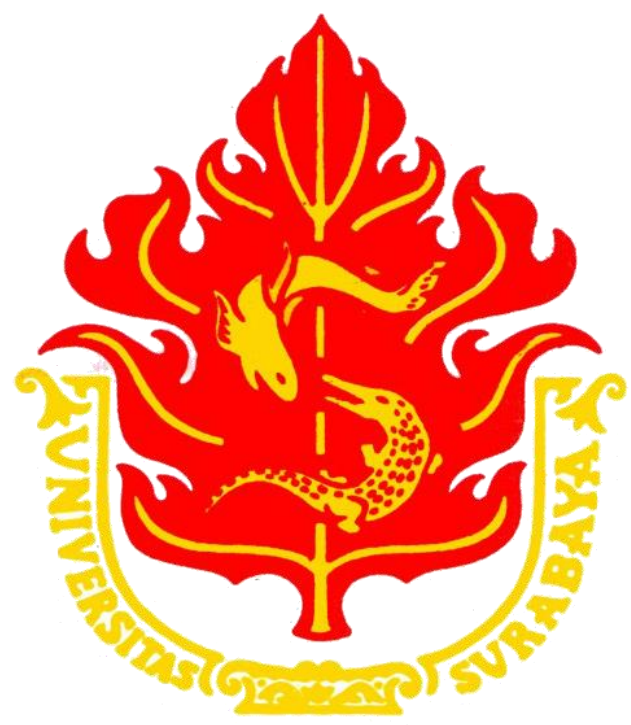

Oleh:

Felicya Christina Wijaya

130218022

KP B

FAKULTAS BISNIS DAN EKONOMIKA

UNIVERSITAS SURABAYA

2021 


\section{COMPANY CHALLENGES IN UNCERTAINTY GLOBAL ECONOMIC}

A.Z. Tayibnapis and LEWuryaningsih said that with the current uncertain world economic conditions, companies can use one alternative to stay afloat with the transformation business, especially by generating new values in every aspect of company performance. Not only that, companies must also improve competence. workers, who are assisted by the development of information and technology that continues to improve.

In 2018, economic conditions in Indonesia tended to slow down and were unstable, with uncertainty stemming from global finance. This can be seen in the World Bank Report which notes that Indonesia is ranked $73^{\text {rd }}$ out of 190 countries in the world related to doing business, down one place from 2017 where Indonesia was ranked $72^{\text {nd }}$. However, this decline did not have a significant impact on both domestic investment and foreign investment.

From 2016-2018, business competition has become increasingly fierce and requires company leaders to be able to optimize the use of resources to be able to continue to innovate and create diversified products, as well as increase benefits for stakeholders. But in reality, there are still many companies that do not know what to do when facing a dynamic global competitive environment, uncertainty in the business world, changing political and social conditions of the country, rapid technological advances, etc. Therefore, companies must make adjustment to adapt to the current business era, by implementing Good Corporate Governance (GCG) which is the basis of operations and guarantees the trust of company stakeholders.

From 2014 to 2017, the population of small, medium and large industries experienced a significant increase. The increase in the small industry sector amounted to 970 thousand, and in the medium to large sector by 5,898 business entities. This increase can be seen in the quality of the workforce in Indonesia which is experiencing development, in addition to that the digital trend that continues to develop also opens up wider job opportunities. The development of technology that continues to advance has created many new jobs, but most of them are informal and do not have a clear legal status, so the existence of this digital technology requires a change in the expertise of human resources who have more competence than before.

The competitiveness of companies in Indonesia is experiencing economic disruption, which means that technological developments in Industry 4.0 aim to be able to maintain, develop, and provide added value to all company stakeholders. One of the problems that will arise when a company plans a new plan is the preparation of a strategy in business processes, organizational structure, HR readiness, and a new corporate culture. A world that is experiencing volatility, uncertainty, complexity, and ambiguity (VUCA) that comes from 
globalization, digitization, and trade wars, this indicates that every company needs an evaluation of the company's transformation in order to adapt the current process. Transformation can be carried out from all aspects, including aspects of the management system, organizational structure, human resources, strategy and funding.

The preparation of a new strategy that currently exists is to implement GCG, with the principles, namely transparency, accountability, responsibility, independence and fairness. Operationally it has been proven that this GCG can help companies to make good corporate strategy and management in creating and introducing new values in products, operations and services which also have an impact on improving company performance, thereby increasing the trust or trust of stakeholders. The implementation of sustainable GCG from a value perspective is urgently needed by the Indonesian state, because it can show that this system is expected to not be able to boost the company's business, but also increase stakeholder confidence so that investors are attracted to the company's shares.

The effectiveness of the organizational structure is also of great concern to investors who will make investment decisions. The implementation of GCG can also help companies improve the quality of business units, because the management system of a company greatly affects the company's performance in achieving the desired goals. Every company needs employee engagement, because the involvement of an employee in an organization can provide access for management to build high commitment, which in turn can be implemented into the company's day-to-day operations. Things like this will be an advantage for a company compared to its competitors so that it can survive both in the domestic market and the global market.

The implementation of GCG has also been proven to increase the disclosure of company information, the effectiveness of the company's audit system, corporate value, as well as risk control. And it is hoped that more and more companies in Indonesia will implement this GCG system with the aim of being able to survive in the current era of business transformation. 